\title{
Suppression effects of dental glass-ceramics with polarization-induced highly dense surface charges against bacterial adhesion
}

\author{
Kosuke NOZAKI ${ }^{1}$, Hiroki KOIZUMI ${ }^{2}$, Naohiro HORIUCHI ${ }^{3}$, Miho NAKAMURA ${ }^{3}$, Toshinori OKURA², \\ Kimihiro YAMASHITA ${ }^{3}$ and Akiko NAGAI ${ }^{1}$ \\ ${ }^{1}$ Department of Material Biofunctions, Institute of Biomaterials and Bioengineering, Tokyo Medical and Dental University, 2-3-10 Kanda-Surugadai, \\ Chiyoda-ku, Tokyo 101-0062, Japan \\ ${ }^{2}$ Nanoceramics Chemistry Laboratory, Applied Chemistry and Chemical Engineering, Kogakuin University, 2665-1 Nakano, Hachioji, Tokyo 192- \\ 0015, Japan \\ ${ }^{3}$ Department of Inorganic Biomaterials, Institute of Biomaterials and Bioengineering, Tokyo Medical and Dental University, 2-3-10 Kanda-Surugadai, \\ Chiyoda-ku, Tokyo 101-0062, Japan \\ Corresponding author, Kosuke NOZAKI; E-mail:k.nozaki.fpro@tmd.ac.jp
}

\begin{abstract}
This study investigated the surface characteristics and antibacterial ability capacity of surface-improved dental glass-ceramics by an electrical polarization process. Commercially available dental glass-ceramic materials were electrically polarized to induce surface charges in a direct current field by heating. The surface morphology, chemical composition, crystal structure, and surface free energy (SFE) were evaluated using scanning electron microscopy, energy dispersive X-ray spectrometry, X-ray diffraction, and water droplet methods, respectively. The antibacterial capacity was assessed by a bacterial adhesion test using Streptococcus mutans. Although the surface morphology, chemical composition, and crystal structure were not affected by electrical polarization, the polar component and total SFE were enhanced. After $24 \mathrm{~h}$ incubation at $37^{\circ} \mathrm{C}$, bacterial adhesion to the polarized samples was inhibited. The electrical polarization method may confer antibacterial properties on prosthetic devices, such as porcelain fused to metal crowns or all ceramic restorations, without any additional bactericidal agents.
\end{abstract}

Keywords: Antibacterial capacity, Glass-ceramics, Surface modification, Surface charge, Surface free energy

\section{INTRODUCTION}

The accumulation of dental biofilm on tooth and prosthetic device surfaces is an important factor in the development of caries and periodontitis ${ }^{1}$. As dental caries is a major cause of failure of all-ceramic restorations and porcelain fused to metal crowns ${ }^{2,3}$, there is increasing interest in using dental materials that might inhibit plaque formation ${ }^{4,5)}$. Antibacterial coatings can be divided into two categories depending on how the antibacterial agent is delivered: active coating and passive coating ${ }^{6}$.

Passive coatings impede bacterial adhesion and/or kill bacteria upon contact without releasing bactericidal agents into the surrounding tissue ${ }^{6}$. During the formation of a dental biofilm on a prosthetic device surface in an oral cavity, four well-defined stages are recognized; transport to the surface, initial adhesion, attachment, and colonization/plaque maturation ${ }^{7}$. The initial adhesion results in a weak and reversible adhesion of the bacteria via their interaction with the surface at a certain distance through long and shortrange forces. Interactions between bacteria and the surfaces of the prosthetic device are thought to be based on a variety of forces, including the Lifshitz-van der Waals, electrostatic, and hydrophobic forces and various specific receptor-ligand interactions ${ }^{8}$. These findings

Color figures can be viewed in the online issue, which is available at J-STAGE.

Received Dec 9, 2014: Accepted May 7, 2015

doi:10.4012/dmj.2014-342 JOI JST.JSTAGE/dmj/2014-342 indicate that the surface characteristics of materials play critical roles in the initial adhesion of bacteria to prosthetic devices and in the subsequent formation of biofilms ${ }^{6)}$.

Dental glass-ceramics, which are mainly composed of silicon dioxide, are one of the most popular materials used in prosthetic devices because of their excellent esthetic value, biocompatibility, and stability ${ }^{9}$. Although in vivo studies have shown that the adhesion of bacteria and bacterial biofilm to glass-ceramics is lower than to other dental materials, such as gold alloy, titanium, amalgam, and resin composite ${ }^{10)}$, further research into strategies to treat bacterial infections is needed because of the risk of material-associated infections ${ }^{11)}$.

Previously, it was reported that some ceramic biomaterials, such as titanium dioxide and zirconia, could be electrically charged by the dipole moment through an electrical polarization process ${ }^{12-15)}$. However, few studies are available on the application of electrical polarization to dental glass-ceramics. Moreover, the effect of electrical polarization on surface characteristics and bacterial adhesion is not yet fully understood. In this study, to create an antibacterial dental glass-ceramic material, we modified dental glass-ceramics using the electrical polarization process and characterized the surface morphology, chemical composition, crystal structure, and surface free energy of the glass-ceramics. The antibacterial capacity of the modified glass-ceramics was assessed by testing the adhesion of the bacterium 
Streptococcus mutans, which is known to cause dental caries.

\section{MATERIALS AND METHODS}

\section{Fabrication of testing materials}

Commercially available dental glass-ceramics (Cerec Blocs S3-M 14, Sirona Dental Systems, Bensheim, Germany) were cut into sections approximately $1 \mathrm{~mm}$ thick with precision diamond saws (IsoMet Low speed Saw, Buehler, IL, USA). The ceramic disks were ground with wet abrasive paper (Wet abrasive paper, Refinetec, Kanagawa, Japan), polished with diamond suspensions to $3 \mu \mathrm{m}$ tolerance (Hyprez Diamond Slurry, Engis, IL, USA). The arithmetic average surface roughness (Ra) of specimens was characterized by laser microscope (VK8510, Keyence, Osaka, Japan).

Surface modification of glass-ceramic disks

In accordance with the electrical polarization process reported in previous studies ${ }^{13,16)}$, the specimens were electrically polarized in a DC field of 0.1 or $1.0 \mathrm{kV} / \mathrm{cm}$ in air at $250^{\circ} \mathrm{C}$ for $1 \mathrm{~h}$. The ceramic surfaces placed in contact with the anode and the cathode were defined as the $\mathrm{N}$-surface and the $\mathrm{P}$-surface, respectively. The control group was prepared using the same equipment by heating without applying the DC voltage (herein, it is termed the H-surface) (Fig. 1).

Surface characterization of polarized glass-ceramic disks The crystal structure, micro structure, and chemical composition of the specimens were evaluated by X-ray

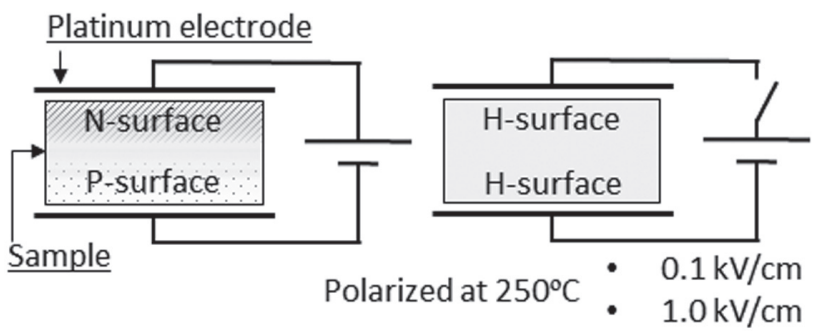

Fig. 1 Schematic illustration for fabrication of specimens. diffraction (XRD, D8 Advance, Bruker, Germany) analysis, scanning electron microscope (SEM, S-3400NX, Hitachi, Japan), and energy dispersive X-ray spectroscopy (EDS, S-3400NX, Hitachi, Oxford Instrument), respectively. Confirmation of the polarization was determined by the thermally stimulated depolarization current (TSDC) as previously described $^{17)}$. The stimulated depolarization current was measured from room temperature to $560^{\circ} \mathrm{C}$ in air at a heating rate of $5.0^{\circ} \mathrm{C} / \mathrm{min}$. The stored charges $(Q)$ were calculated from TSDC spectra using the equation

$$
Q=1 / \beta \int J(T) d T
$$

where $J(T)$ is the measured depolarization current density at temperature $T$ and $\beta$ is the heating rate.

\section{Surface free energy (SFE)}

The SFE of the specimens was evaluated by the OwensWendt method ${ }^{18)}$. The static contact angles of the specimens $(n=30)$ were measured according to the sessile drop technique using a contact angle meter (DM-301, Kyowa Interface Science, Saitama, Japan) with water, formamide (Wako Pure Chemical Industries, Osaka, Japan), and diiodomethane (Wako).

\section{Bacterial adhesion test}

Before testing bacterial adhesion, the specimens were immersed in artificial saliva ${ }^{19,20}$ (Table 1) with or without $1.4 \mathrm{wt} \%$ mucin suspension (Mucin from porcine stomach, Type II, Sigma-Aldrich, Mo, USA) at $37^{\circ} \mathrm{C}$ for $1 \mathrm{~h}$ to form a coating of salivary conditioning film.

The Streptococcus mutans MT 8148 (S. mutans) bacterium (kindly provided by Prof. Ichiro NAKAGAWA of Tokyo Medical and Dental University) were incubated in brain-heart infusion (BHI, Bacto Brain Heart Infusion, Becton, Dickinson and Company, Sparks, USA) broth at $37^{\circ} \mathrm{C}$ for $24 \mathrm{~h}$ to obtain $10^{9}$ colony forming units (CFU)/mL bacterial suspension. The bacterial suspension was added to each well to cover all specimen surfaces and incubated at $37^{\circ} \mathrm{C}$ for $24 \mathrm{~h}$. The specimens $(n=60)$ were then gently washed with PBS, stained using acridine orange solution (-Bacstain- AO solution, Dojindo Laboratories, Kumamoto, Japan), and observed under a fluorescence microscope (Fluoview FV10i,

Table 1 Chemical composition of artificial saliva

\begin{tabular}{lcc}
\hline \multicolumn{1}{c}{ Material } & Concentration $(\mathrm{g} / \mathrm{L})$ & Manufacturer \\
\hline $\mathrm{NaCl}$ & 0.4 & Wako Pure Chemical Industries \\
$\mathrm{KCl}$ & 0.4 & Wako Pure Chemical Industries \\
$\mathrm{CaCl}_{2}\left(\mathrm{H}_{2} \mathrm{O}\right)$ & 0.795 & Wako Pure Chemical Industries \\
$\mathrm{NaH}_{2} \mathrm{PO}_{4}\left(\mathrm{H}_{2} \mathrm{O}\right)$ & 0.69 & Kanto Chemical \\
$\mathrm{Na}_{2} \mathrm{~S}$ & 0.005 & Wako Pure Chemical Industries \\
$\mathrm{Urea}$ & 1 & Wako Pure Chemical Industries \\
\hline
\end{tabular}


Olympus, Tokyo, Japan). The amount of bacterial adhesion was estimated from the positive area ratio of acridine orange.

\section{Statistical analysis}

The chemical composition of each surface was analyzed via one-way analysis of variance (ANOVA) followed by a Tukey HSD test. A two-way ANOVA was used to assess significant differences between the means of the studied polar component, dispersive component, and total SFE (applied voltage and surface polar character). A threeway ANOVA was used to assess significant differences in the means of the positive area ratio among selected factors (applied voltage, surface polar character, and mucin coating). When no interaction was found, a one-way ANOVA followed by a $t$-test with Bonferroni correction was used to assess for significant differences between the different applied voltage and surface polar character conditions. $p<0.05$ was considered statistically significant.

\section{RESULTS}

\section{Surface characterization}

The average surface roughness of polished dental glassceramics used in this study was $0.23 \pm 0.02 \mu \mathrm{m}$. The SEM micrographs of dental glass-ceramic surfaces with or without a DC field are shown in Fig. 2. All sample surfaces were relatively smooth but presented some polishing flaws. There were no remarkable changes between before and after applying electrical fields. Any changes in the chemical composition of the surfaces were explored by EDS analysis (Table 2). The glassceramic block used in this study was composed of sodium, potassium, silicon, and calcium. There were no significant differences in the chemical composition of the polarized $(1.0 \mathrm{kV} / \mathrm{cm})$ and non-polarized specimens $(0$ $\mathrm{kV} / \mathrm{cm})$. The crystal structures of the polarized $(1.0 \mathrm{kV} /$ $\mathrm{cm})$ and non-polarized glass-ceramic blocks were mainly nepheline $\left((\mathrm{Na}, \mathrm{K}) \mathrm{AlSiO}_{4}\right)$ and anorthoclase $((\mathrm{Na}, \mathrm{K})$ $\mathrm{AlSi}_{3} \mathrm{O}_{8}$ ) as measured by XRD analysis (Fig. 3).

\section{Surface charges of polarized glass-ceramics}

The behavior of a polarized material can be estimated
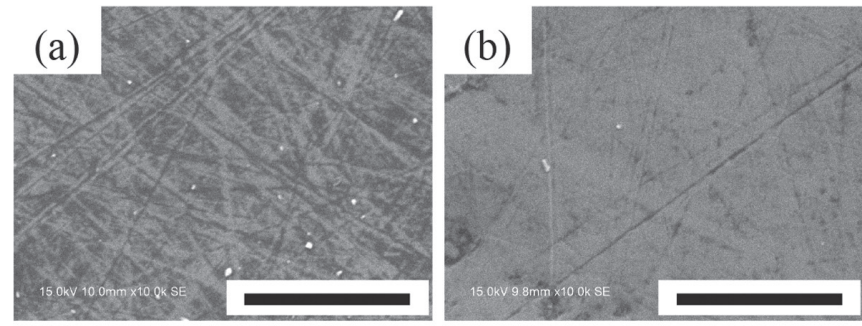

\section{(d)}

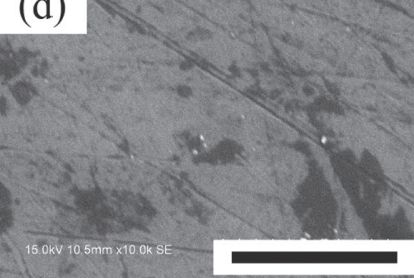

(c)

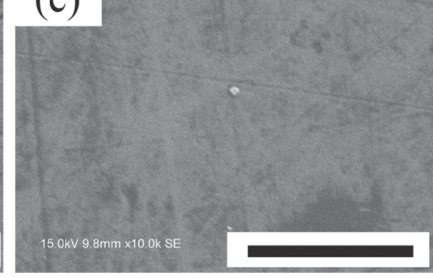

(e)



Fig. 2 SEM images of dental glass-ceramics modified through the electrical polarization process.

(a) H-surface, (b, d) N-surface, (c, e) P-surface, (b, c) $0.1 \mathrm{kV} / \mathrm{cm}$, (d, e) $1.0 \mathrm{kV} / \mathrm{cm}$, Bar, $5 \mu \mathrm{m}$.

Table 2 Chemical composition of non-polarized and polarized dental glass-ceramics analyzed by energy dispersive X-ray spectrometry

\begin{tabular}{cccc}
\hline Element & H-surface & N-surface & P-surface \\
\hline $\mathrm{Na}$ & $10.7 \pm 0.8$ & $11.5 \pm 0.2$ & $10.7 \pm 0.9$ \\
$\mathrm{Al}$ & $20.4 \pm 0.6$ & $21.5 \pm 0.3$ & $20.5 \pm 1.5$ \\
$\mathrm{Si}$ & $60.5 \pm 0.7$ & $58.8 \pm 0.8$ & $60.2 \pm 2.1$ \\
$\mathrm{~K}$ & $8.0 \pm 0.5$ & $7.4 \pm 0.2$ & $8.2 \pm 0.4$ \\
$\mathrm{Ca}$ & $0.4 \pm 0.2$ & $0.7 \pm 0.0$ & $0.4 \pm 0.2$ \\
\hline
\end{tabular}




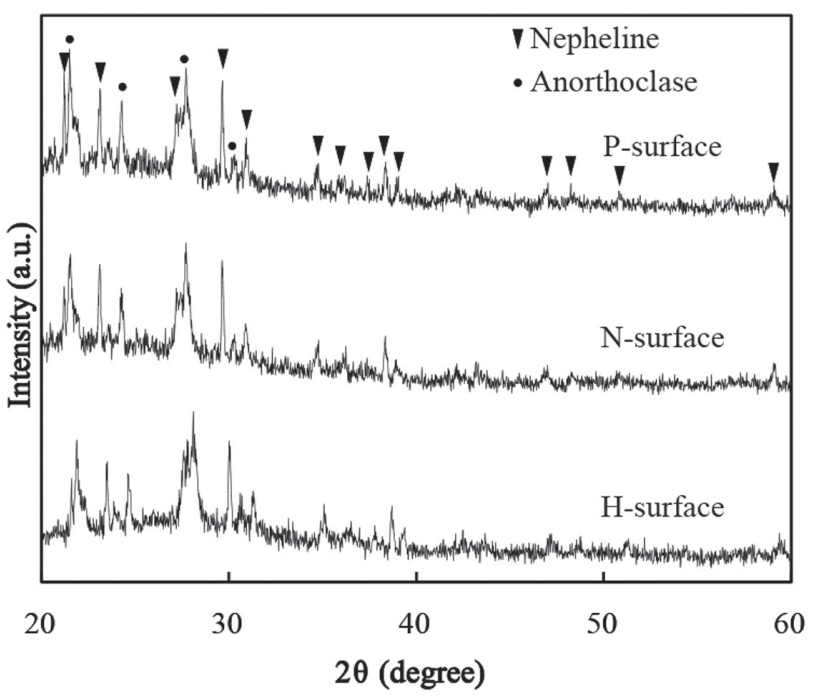

Fig. 3 XRD results of non-polarized and polarized dental glass-ceramics.

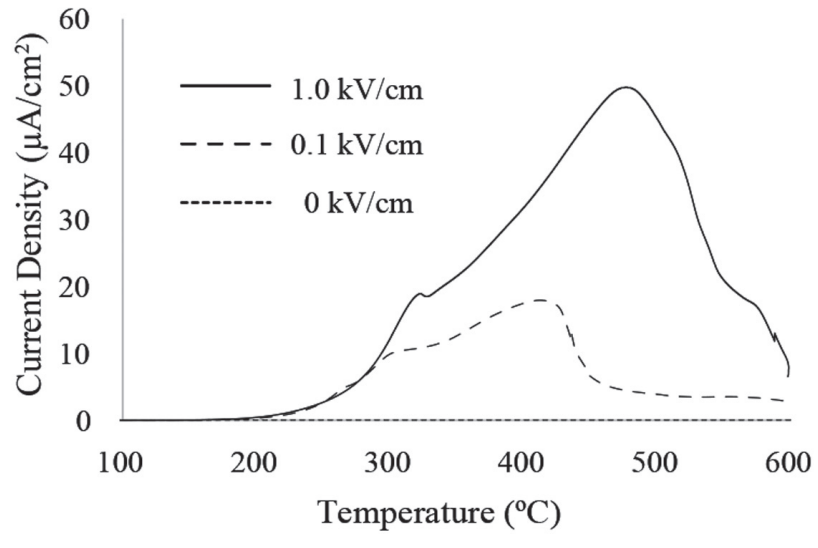

Fig. 4 Representative thermally stimulated depolarization current (TSDC) spectra of nonpolarized and polarized specimens.

Table 3 The polar and dispersive component and total surface free energy (SFE) of modified dental glass-ceramics

\begin{tabular}{lccccc}
\hline \multicolumn{1}{c}{ Surface character } & H-surface & \multicolumn{2}{c}{ N-surface } & \multicolumn{2}{c}{ P-surface } \\
\hline Applied voltage $(\mathrm{kV} / \mathrm{cm})$ & \multicolumn{1}{c}{0} & 0.1 & 1.0 & 0.1 & 1.0 \\
Polar component $\left(\mathrm{mJ} / \mathrm{m}^{2}\right)$ & $9.5 \pm 2.3$ & $21.9^{*} \pm 5.3$ & $18.9^{*} \pm 4.8$ & $19.9^{*} \pm 4.4$ & $18.9^{*} \pm 6.5$ \\
Dispersive component $\left(\mathrm{mJ} / \mathrm{m}^{2}\right)$ & $34.4 \pm 2.5$ & $28.4 \pm 3.4$ & $28.0 \pm 2.0$ & $28.4 \pm 3.4$ & $28.1 \pm 4.9$ \\
Total SFE $\left(\mathrm{mJ} / \mathrm{m}^{2}\right)$ & $43.9 \pm 1.0$ & $49.1^{*} \pm 2.9$ & $48.3^{*} \pm 1.7$ & $47.0^{*} \pm 2.9$ & $47.0^{*} \pm 1.7$ \\
\hline
\end{tabular}

$*: p<0.05$.

by TSDC measurements. Representative TSDC spectra of the polarized and non-polarized dental glass-ceramics are shown in Fig. 4. The depolarization current of the polarized samples was observed at $c a .200^{\circ} \mathrm{C}$ and reached at maximum value at $\mathrm{ca} .420^{\circ} \mathrm{C}(0.1 \mathrm{kV} / \mathrm{cm})$ and $480^{\circ} \mathrm{C}$ $(1.0 \mathrm{kV} / \mathrm{cm})$. The stored charges of the $0,0.1$ and $1.0 \mathrm{kV} /$ $\mathrm{cm}$ samples were 0,37 and $103 \mathrm{mC} / \mathrm{cm}^{2}$, respectively. The half-lives of the 0.1 and $1.0 \mathrm{kV} / \mathrm{cm}$ samples at $37^{\circ} \mathrm{C}$ were 1 and 65 years, respectively.

\section{SFE of polarized glass-ceramics}

The surface free energies were calculated using the Owens-Wendt method and are shown in Table 3 . Because the interactions in the polar component, dispersive component, and the total SFE between the surface character and the applied voltage were not significant, the SFE was evaluated by one-way ANOVA followed by Bonferroni multiple comparison test. The polar component and the total SFE were enhanced by an electrical polarization applied at voltages of 0.1 and $1.0 \mathrm{kV} / \mathrm{cm}$. However, the SFEs were not affected by the polar character (N- and $\mathrm{P}$-surface). Furthermore, we evaluated the effect of the amount of applied voltage on the SFEs. There were no significant differences between the polar components, dispersive components and total SFEs for both applied voltages $(0.1$ and $1.0 \mathrm{kV} / \mathrm{cm})$.

\section{Bacterial adhesion test}

The degree of bacterial adhesion was evaluated by the positive area ratio of acridine orange solution (Figs. 5 and 6). The means and SDs of the positive area ratio are presented in Fig. 7. Because the interactions (surface character $v s$. applied voltage, surface character $v s$. mucin coatings, applied voltage vs. mucin coatings, and surface character $v s$. applied voltage $v s$. mucin coating) in the positive area ratio were not significant, we evaluated the positive area ratio by one-way ANOVA followed by a Bonferroni multiple comparison test. Regardless of the presence or absence of a mucin coating, bacterial adhesion was inhibited by the electrical polarization process. The polar character, the amount of applied voltage, and the presence of a mucin coating had little effect on bacterial adhesion. 

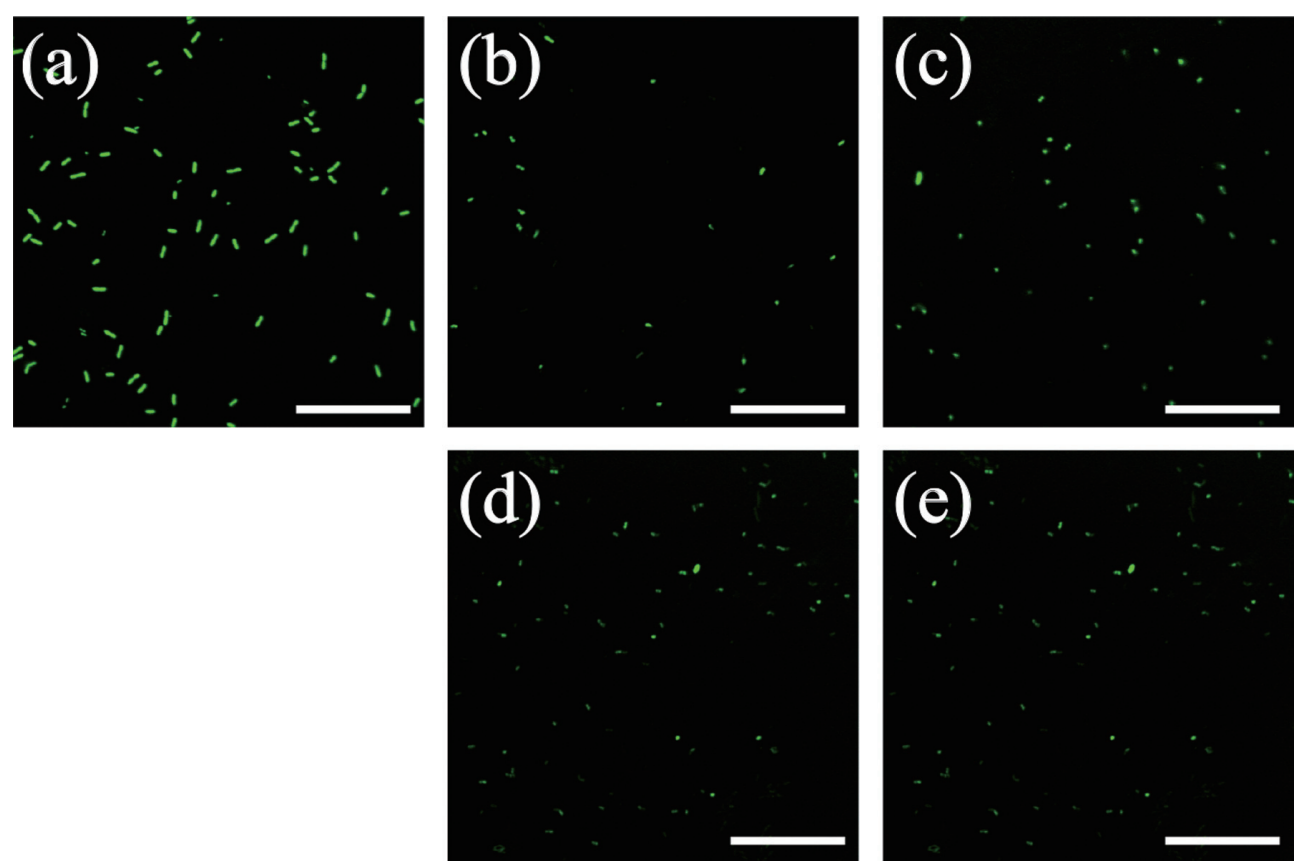

Fig. 5 Fluorescence microscope images of adherent bacteria on the dental glass-ceramics coated without mucin suspension.

(a) H-surface, (b, c) $0.1 \mathrm{kV} / \mathrm{cm}$, (d, e) $1.0 \mathrm{kV} / \mathrm{cm}$, (b, d) N-surface, (c, e) P-surface. Bacteria were stained with acridine orange solution (green). Bar, $30 \mu \mathrm{m}$.
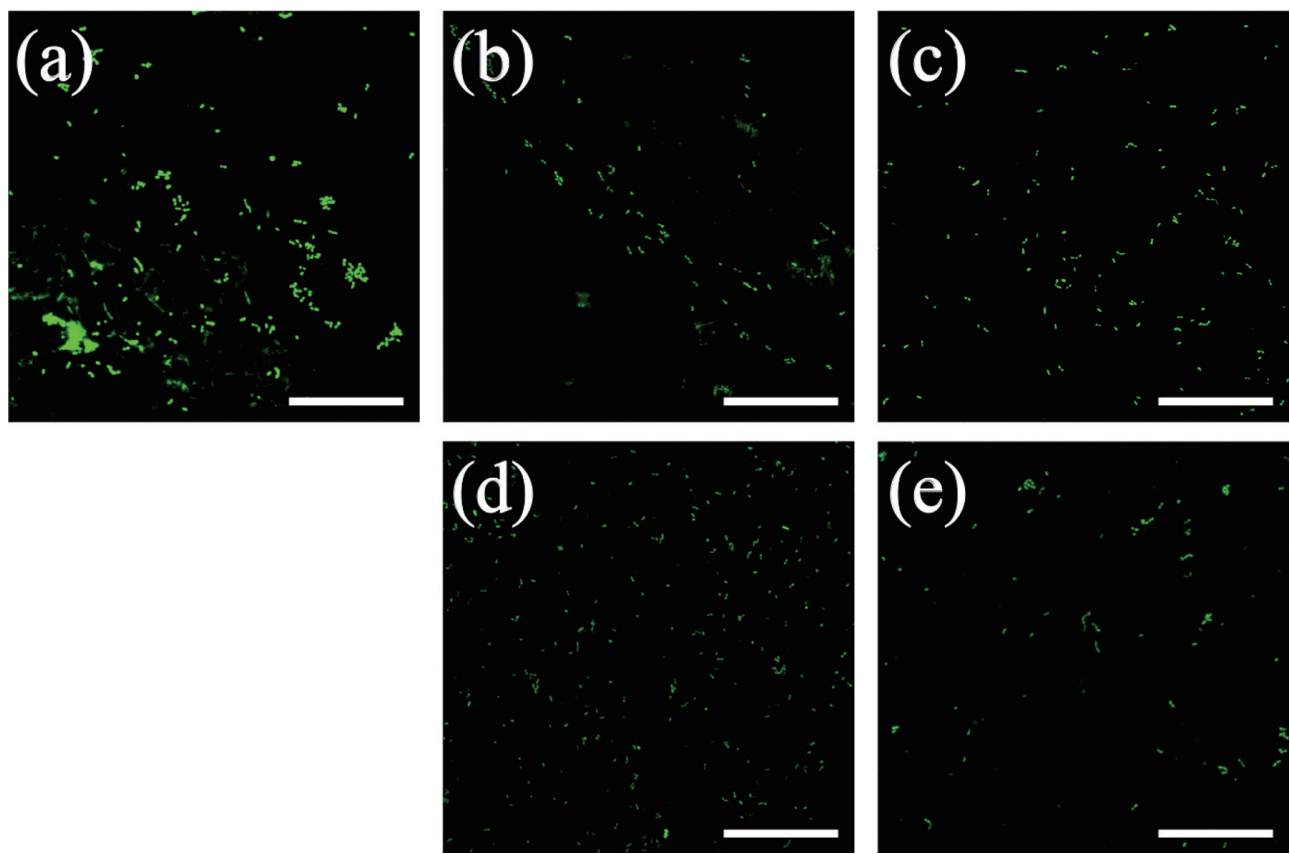

Fig. 6 Fluorescence microscope images of adherent bacteria on the dental glass-ceramics coated with mucin suspension.

(a) H-surface, (b, c) $0.1 \mathrm{kV} / \mathrm{cm}$, (d, e) $1.0 \mathrm{kV} / \mathrm{cm}$, (b, d) N-surface, (c, e) P-surface. Bacteria were stained with acridine orange solution (green). Bar, $30 \mu \mathrm{m}$. 

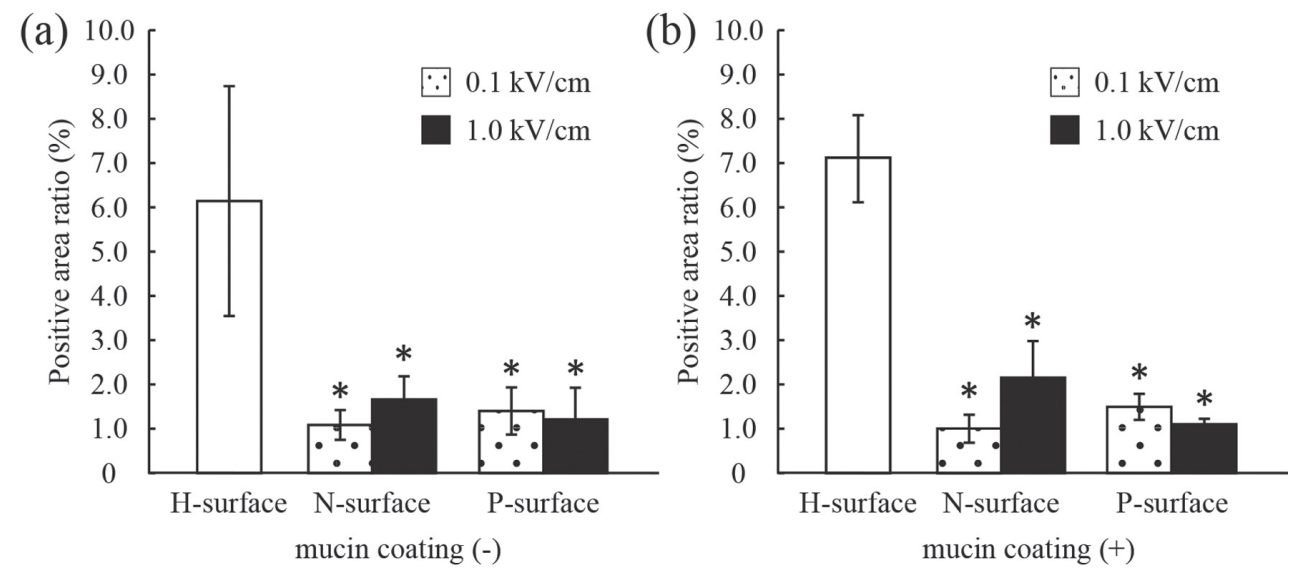

Fig. 7 The quantity of bacterial adhesion to the dental glass-ceramics. *: $p<0.05$

\section{DISCUSSION}

The results of this study indicate that the electrical polarization process offers promise as a noninvasive surface modification method to impart antibacterial properties to dental glass-ceramics. Antibacterial biomaterial strategies for the prevention of infections are divided into two types based on the mechanisms of biofilm formation: bactericidal/bacteriostatic coatings and anti-adhesion coating ${ }^{21,22)}$. Anti-adhesion coatings are achieved by surface modifications to directly alter surface properties, including chemical composition and reactivity, hydrophilicity and hydrophobicity, surface roughness or texture, and surface charge ${ }^{22)}$. Although certain polymer coatings, such as hydrophilic polymethacrylic acid, polyethylene oxide or proteinresistant polyethylene glycol, provide significant inhibition of bacterial adhesion ${ }^{6}$, their stability in the oral environment is not well understood. In this study, to estimate the sustainability of the antibacterial effect, the half-lives of polarized samples at $37^{\circ} \mathrm{C}$ were analyzed from the TSDC measurements. Although many studies have reported on the survival rates of porcelain-fused metal crowns and all-ceramic restorations, no long term (i.e., over 20-years) clinical trials have been conducted ${ }^{2,3}$. Polarized samples prepared with $1.0 \mathrm{kV} / \mathrm{cm}$ voltage showed sustained, controlled surface charges for over 20 years, indicating that a $1.0 \mathrm{kV} / \mathrm{cm}$ application of electrical polarization can confer antibacterial properties.

The surface charges of dental glass-ceramics were controlled through the electrical polarization process. Electrical polarization using an external electric field can manipulate the electric dipoles; subsequently, stored surface charges are observed by TSDC ${ }^{13)}$. The TSDC spectra of polarized dental glass-ceramics showed several peaks characteristic of charge carriers. In an earlier study, we successfully controlled alkali ions in 45S5-type bioactive glass through the electrical polarization process ${ }^{16)}$. The glass phase of dental glass- ceramics contains alkali oxides, such as sodium and potassium oxide, which can move through the network of the glass matrix ${ }^{23}$. Alkali ion carriers have been reported to jump among sites around the non-bridging oxygen ions by an applied DC field during the electrical polarization process ${ }^{24)}$. Electrical polarization using an external electric field also controls the dipoles in the crystal ${ }^{25)}$. Furthermore, dental glass-ceramics also contain a crystal phase ${ }^{26)}$. Anorthoclase and nepheline constitute the crystal phase of dental glass-ceramics. They are part of the alkali feldspar group and contain sodium and potassium ions, which are dominant charge carriers in feldspar minerals ${ }^{27}$. Therefore, the major charge carriers in dental glass-ceramics are sodium and potassium ions. Additional studies will be required to identify the factors that contribute to the temperaturedependent peaks in the TSDC spectra.

Electrical polarization can be used to alter the SFE of dental glass-ceramics without physically changing the surface structure, the chemical composition or the crystal structure. SFE is a thermodynamic approach that describes the equilibrium state of atoms in the surface layer of a material ${ }^{28}$. The Owens-Wendt method determines the dispersion and polar components of SFE from the measurements of the contact angle in bipolar and polar liquids ${ }^{18}$. Some of the factors that have an impact on the measured value of the contact angle include surface roughness and physical and chemical homogeneity ${ }^{28)}$. In this experiment, surface roughness was relatively uniform for all samples and was also found to be equally smooth after SEM analyses. Furthermore, EDS and XRD analyses showed no obvious difference in the surface structure and crystal structure among the samples. These results suggest that electrical polarization alters the SFE by manipulating the dipoles moments in dental glass-ceramics.

Electrical polarization reduced bacterial adhesion to dental glass-ceramics even in the presence of mucin protein coating. Biofilm formation in the oral cavity is 
initiated by the adsorption of salivary proteins and oral bacteria onto a tooth or prosthetic device surface ${ }^{29)}$. The mucins are a family of heavily glycosylated proteins, which are the major organic components of saliva. Because they contain substantial amounts of sialic acid and sulfate residues ${ }^{30}$, mucin coatings confer a negative charge to all surfaces, and then electrostatic interaction will take place. Although electrostatic repulsive forces exist between negatively-charged bacteria and mucinfree $\mathrm{N}$-surfaces or mucin-coated $\mathrm{N}$ and $\mathrm{P}$-surfaces ${ }^{7}$, our data showed that the amount of bacterial adhesion to mucin-free $\mathrm{N}$-surface and mucin-coated substrates was not significantly different from that adhered to mucinfree P-surface and mucin-free substrates, respectively. The amount of bacterial adhesion in this study may depend on not only an initial adhesion but also a detachment caused by wash protocol. The detachment strength of bacteria from a substrate is associated with a surface wettability ${ }^{311}$. Due to the hydrophilicity of polarized samples with no relation to their polar character, adhering bacteria were more readily detached from the polarized samples than from non-polarized glass-ceramics.

\section{CONCLUSION}

In conclusion, this study provides new and important methods for the surface modification dental glassceramics to inhibit bacterial adhesion, including mucinaided adhesion. The electrical polarization process mediates dipole behavior in the dental glass-ceramics and increases the surface free energy without the need for additional agents. Furthermore, this process avoids the alteration of the surface chemical composition, crystal structure, or morphology. However, the antibacterial effect of this method on polarized dental glass-ceramics coated with several oral salivary proteins is unclear and warrants further examination in vivo.

\section{ACKNOWLEDGMENTS}

This study was partially supported by a JSPS Grant-inAid for Scientific Research (B) Grant Number 23300178 and a Grant-in-Aid for Scientific Research (C) Grant Number 26462964. The authors are grateful to Prof. NAKAGAWA for his assistance with the bacterial adhesion test.

\section{CONFLICTS OF INTEREST}

The authors declare no conflicts of interest.

\section{REFERENCES}

1) Lindhe J, Lang NP, Karring T. Clinical periodontology and implant dentistry: Wiley. com; 2009.

2) Beier US, Kapferer I, Dumfahrt H. Clinical long-term evaluation and failure characteristics of 1,335 all-ceramic restorations. Int J Prosthodont 2012; 25: 70-78.

3) Behr M, Zeman F, Baitinger T, Galler J, Koller M, Handel G, Rosentritt M. The clinical performance of porcelain-fused- to-metal precious alloy single crowns: chipping, recurrent caries, periodontitis, and loss of retention. Int J Prosthodont 2014; 27: 153-160.

4) Pereira-Cenci T, Cenci MS, Fedorowicz Z, Azevedo M. Antibacterial agents in composite restorations for the prevention of dental caries. Cochrane Database Syst Rev 2009; 12: CD007819.

5) Wang Z, Shen Y, Haapasalo M. Dental materials with antibiofilm properties. Dent Mater 2014; 30: e1-16.

6) Goodman SB, Yao Z, Keeney M, Yang F. The future of biologic coatings for orthopaedic implants. Biomaterials 2013; 34: 3174-3183.

7) Teughels W, Van Assche N, Sliepen I, Quirynen M. Effect of material characteristics and/or surface topography on biofilm development. Clin Oral Implants Res 2006; 17: 68-81.

8) Harris LG, Tosatti S, Wieland M, Textor M, Richards RG. Staphylococcus aureus adhesion to titanium oxide surfaces coated with non-functionalized and peptide-functionalized poly(L-lysine)-grafted-poly(ethylene glycol) copolymers. Biomaterials 2004; 25: 4135-4148.

9) Van Noort R. Introduction to dental materials 4: Introduction to Dental Materials: Elsevier Health Sciences; 2013.

10) Auschill TM, Arweiler NB, Brecx M, Reich E, Sculean A, Netuschil L. The effect of dental restorative materials on dental biofilm. Eur J Oral Sci 2002; 110: 48-53.

11) Cabal B, Alou L, Cafini F, Couceiro R, Sevillano D, EstebanTejeda L, Guitián F, Torrecillas R, Moya JS. A new biocompatible and antibacterial phosphate free glass-ceramic for medical applications. Sci Rep 2014; 4: 5440.

12) Yamashita K. Concept and development of vector ceramics for biointerface engineering. J Ceram Soc Jpn 2005; 113: 1-9.

13) Yamashita K, Oikawa N, Umegaki T. Acceleration and deceleration of bone-like crystal growth on ceramic hydroxyapatite by electric poling. Chem Mater 1996; 8: 2697 2700 .

14) Nagai A, Yamazaki Y, Ma CF, Nozaki K, Toyama T, Yamashita K. Response of osteoblast-like MG63 cells to TiO2 layer prepared by micro-arc oxidation and electric polarization. J Eur Ceram Soc 2012; 32: 2647-2652.

15) Nozaki K, Wang W, Horiuchi N, Nakamura M, Takakuda K, Yamashita K, Nagai A. Enhanced osteoconductivity of titanium implant by polarization-induced surface charges. J Biomed Mater Res A 2014; 102: 3077-3086.

16) Obata A, Nakamura S, Yamashita K. Interpretation of electrical polarization and depolarization mechanisms of bioactive glasses in relation to ionic migration. Biomaterials 2004; 25: 5163-5169.

17) Nakamura S, Takeda H, Yamashita K. Proton transport polarization and depolarization of hydroxyapatite ceramics. J Appl Phys 2001; 89: 5386-5392.

18) Owens DK, Wendt RC. Estimation of the surface free energy of polymers. J Appl Polymer Sci 1969; 13: 1741-1747.

19) Geis-Gerstorfer J, Weber H. [Effect of potassium thiocyanate on corrosion behavior of non-precious metal dental alloys]. Dtsch Zahnarztl Z 1985; 40: 87-91.

20) Huang HH, Chiu YH, Lee TH, Wu SC, Yang HW, Su KH, Hsu CC. Ion release from NiTi orthodontic wires in artificial saliva with various acidities. Biomaterials 2003; 24: 3585-3592.

21) Bumgardner JD, Adatrow P, Haggard WO, Norowski PA. Emerging antibacterial biomaterial strategies for the prevention of peri-implant inflammatory diseases. Int J Oral Maxillofac Implants 2011; 26: 553-560.

22) Chen M, Yu Q, Sun H. Novel strategies for the prevention and treatment of biofilm related infections. Int J Mol Sci 2013; 14: 18488-18501.

23) Eldin FME, El Alaily NA. Electrical conductivity of some alkali silicate glasses. Mater Chem Phys 1998; 52: 175-179.

24) Obata A, Nakamura S, Moriyoshi Y, Yamashita K. Electrical polarization of bioactive glass and assessment of their in vitro 
apatite deposition. J Biomed Mater Res A 2003; 67A: 413420.

25) Horiuchi N, Tsuchiya Y, Nozaki K, Nakamura M, Nagai A, Yamashita K. Thermally stimulated depolarization current measurements in cubic and tetragonal yttria-stabilized zirconia. Solid State Ionics 2014; 262: 500-503.

26) Shenoy A, Shenoy N. Dental ceramics: An update. J Conserv Dent 2010; 13: 195-203.

27) Hu H, Li H, Dai L, Shan S, Zhu C. Electrical conductivity of alkali feldspar solid solutions at high temperatures and high pressures. Phys Chem Minerals 2013; 40: 51-62.

28) Rudawska A, Jacniacka E. Analysis for determining surface free energy uncertainty by the Owen-Wendt method. Int J Adhes Adhes 2009; 29: 451-457.

29) Hannig C, Hannig M. The oral cavity —a key system to understand substratum-dependent bioadhesion on solid surfaces in man. Clin Oral Investig 2009; 13: 123-139.

30) Derrien M, van Passel MW, van de Bovenkamp JH, Schipper RG, de Vos WM, Dekker J. Mucin-bacterial interactions in the human oral cavity and digestive tract. Gut microbes 2010; 1: 254-268.

31) Boks NP, Norde W, van der Mei HC, Busscher HJ. Forces involved in bacterial adhesion to hydrophilic and hydrophobic surfaces. Microbiology 2008; 154: 3122-3133. 